\title{
Student-centered Role-based Case Study Model to Improve Learning in Decision Support Systems
}

\author{
Farrukh Nadeem, Salma Mahgoub \\ Department of Information Systems, Faculty of Computing and Information Technology, King Abdulaziz University, \\ Jeddah, Saudi Arabia. \\ Email: fabdullatif@kau.edu.sa, smomar@kau.edu.sa
}

\begin{abstract}
One of the important learning objectives of our bachelor course on "Techniques in Decision Support Systems" is to develop understanding of core decision making process in real-life business situations. The conventional teaching methods are unable to explain complexities of real-life business. Although the classroom discussions can be effective to understand general factors, such as opportunity cost, return on investment, etc. affecting business decisions, the effects of factors like dynamic business environment, incomplete information, time pressure etc. can not be truly explained through such simple discussions. In this paper, we describe our experience of adopting student-centered, role-based, case study to deal with this situation. The interactive case-based study not only provided students with experiential learning, but also gave them liberty to test their thoughts. As a result, we observed improved students' learning as well as improved grades. In addition, this approach made classes more dynamic and interesting.
\end{abstract}

Index Terms - Student-centered study, role-based case study, Interactive case-based study, decision support systems, business decision making.

\section{INTRODUCTION}

Techniques in Decision Support Systems (TDSS), a three credit-hours bachelor course at department of Information Systems, Faculty of Computing and IT, aims to educate students about different models and methods for managerial decision making in real-life business situations. The course enables them to design and implement computerized systems and to use them to support business managers in the decision making process.

The core concepts of managerial decision making rest upon the understanding of business environment and factors influencing decision making process including globalization, time pressure, intense competitions, changing customer demands, availability of organizational resources, availability of required information, ongoing technological innovations etc. Teaching managerial decision making process in the light of influencing factors (IFs) is a challenging job due to the complex relationship of target problem or opportunity and IFs. In addition, explaining the varying degree of IFs, which largely depends on the business situation at hand and end goals, make the teaching job even tough.

The choice of an instruction model determines the success or failure in achieving the course learning objectives. It is mainly driven by goals of instruction and current state of knowledge and experience, and needs of students with respect to target course contents [1, 3]. If the main goal is to prepare the students for a certain set of knowledge, inferences and conclusions, classical teachercentered models can easily serve the purpose. However, in our case, where students without any prior experience of real-life business environment are required to comprehend the complex business situations, teachercentered and even simple student-centered teaching models do not suffice to paint the true picture of complexities of real-life business situations [2]. To address this problem, we adopted student-centered rolebased case study (RBCS) model where students studied complex decision making concepts by performing decision makers' roles in the given business cases. To this end, we selected different real-life business cases typically reflecting complex decision making situations and included necessary contextual details. The students were assigned different roles e.g. CEO, finance manager, sales manager, etc. responsible for making decisions in the case situations. For each case study, the students studied the given case, gathered more information (if required) and performed their assigned roles in case discussion meetings (in the class room) to solve the case. This practice of case studies not only raised the student involvement to the maximum, but also made the whole learning process interesting and fun, as the students had a feeling that they are the center of the whole process. The students were able to easily realize the complex effects and interdependencies of IFs in real-world environments. To gauge the effectiveness of this approach, we compared the performance of two undergraduate sections, one of which was taught using classical approach and the second using the proposed model. We found that the results of the section taught using the proposed model were 32\%, on average, better than those of other section in quizzes, assignments as well as mid-term and final exams. We also gathered Likert-scaled [14] students' response 
through a survey about their experience of the case based study approach and found that students also realize a considerable improvement in their learning of complex concepts in this course.

The rest of this paper is organized as follows. Next Section describes the proposed model of student-centered role-based case studies and it major characteristics. Section next to it describes our experience of adopting the proposed model including preparing students for case based study, case discussions, and teacher's feedback on case discussions. In the section afterwards, to approximate the effectiveness of our approach, we present our experimental and survey results. Finally, we conclude in the last Section.

\section{STUDENT-CENTERED RBCS MODEL}

Generally, cases are particular events happened in past, and described like stories. The business cases are typically based on business problems that require some decision making. They also include necessary context of the problem, related IFs, and details of the people responsible for making decisions.

Classical case-based learning was first introduced in law schools in late 1800's and in early 1900's [10]. Later, after its successful use to train a variety of professionals, like instructional designers, pre-service teachers, lawyers, doctors, businessmen, etc. [6, 16, 17, 18]. It also became popular and widely used in teaching business courses. Case-based teaching helps students to develop skills in analytical thinking and reflective judgment by reading and discussing complex, real-life scenarios [21,6]. The case studies are distinguished due to their studentcentered nature, i.e. case contents shift responsibility of learning and searching for required information to the students [12].

RBCS is a transformative strategy that contributes to supporting students' learning [15]. Mezirow [16] defined transformative learning as "the process of using a prior interpretation to construe a new or revised interpretation of the meaning of one's experience in order to guide future action". In RBCS, students study past cases by performing different roles of decision makers involved in the case situation. Every student prepares for his/her role in the case and has to advocate objectives of the assigned role. In this way, students also come to know that in real world everyone involved in decision making process want to optimize the case solution according to one's role in the organization and the final decision should be based on the consideration. In some situations, certain factors have to be optimized while compromising others. In others, a balance between the contradictory goads has to be reached. RBCS forces students to acquire an ability to conceive, implement and critically explore assumptions they were using in problem solving [15]. The main goal of our RBCS approach was to teach different decision making skills and models through real-world examples. Isolated concepts, information, and facts of the target subject are very difficult to understand and remember [7]. Through cases, complex concepts are understood easily, and by repeated application of these concepts in a number of cases they become a part of students' memory for a long time. In addition, through case studies, we focused on the required key concepts/skills only, and in turn reduced the potential for inert knowledge that can be expressed and learnt but cannot be applied to realistic situations, mainly because it had been learnt out of a proper context or relation to reality [9].

We characterize our model in detail in the following subsections.

\section{A. Selection of Business Cases}

The cases selected for our TDSS course were factbased, data-rich, complex business situations with the end goal of either to solve a problem or decide to avail an opportunity or not. The cases were written in a fashion that stimulated discussion [5] among the participants (course students in our case) and led towards collaborative analysis of the case situation. The real context of the problem, as described in each case, provided a concrete framework of the problem and was therefore more motivational to the students. Our cases, especially, were designed to target at the student-centered exploration of real-world business situations that highlight complexity of decision making situations, difficulties in making decisions, relevant importance of different IFs and importance of computerized support in making decisions.

We selected cases with two different orientations.

1. The cases with complete information leading to a predefined set of inferences/conclusions. The students could quickly understand them and solved the problem(s) posed there in.

2. The cases with incomplete information that engaged students in debate through possible reasoning and thus reach some decision $[8,19]$.

Some cases even raised some questions with no single right answer. These cases lead to open a debate to highlight different possibilities. The analysis of realworld situations in these cases helped students in developing their abilities to orchestrate, apply and evaluate their concepts learned throughout the course.

\section{B. Students' Role in RBCS Model}

Students' participation is the most important part in RBCS model. In contrast to classical case-based learning, we engaged students in the case situations by assigning them different roles aligned with the characters of the case. According to their assigned roles, the students identify problems and issues in the case. Many times students needed more information than available in the case, to discuss the case. They searched and gathered this information by themselves. While playing their role in the case, the students raise points, question other roles in the case, and defend their positions. In concluding a case, they devise strategies to analyze the case data and suggest possible solutions for different scenarios of the case. In case of disagreement among students a compromise is 
reached.

\section{Instructor's Role in RBCS Model}

Our proposed model also helped instructors to bring to life and explain abstract concepts and complex situations, and guide students to make effective decisions keeping in mind complex human dilemmas $[4,20,22]$. The instructor of the course acted as a facilitator during the whole exercise. In the course of case proceedings, he encouraged exploration of the case, discussion over important points and supervised actions of the participants in the light of the adopted solution of the case as well as his own knowledge and experiences. At times, he guided the participants to emphasize on more important points. Sometimes, he also directed them to disregard points of less importance and move on to other issues. At the same time, the instructor also ensured that the discussion did not turn towards undesired issues. In case of any dispute or conflict he tried to diffuse the tension, possibly with some humor. During case study, the instructor exploited the opportunities to highlight important concepts in the course. He also facilitated and guided the students in case they found themselves unable to draw concrete and logical conclusions.

\section{EXPERIMENTS AND RESULTS OF ADOPTING RBCS MODEL IN TDSS COURSE}

\section{A. Preparing Students for RBCS}

The students in our class had no previous experience of case studies. They were accustomed to traditional lecturebased classes and to study only before quizzes and exams Breaking this pattern was the most difficult task since in RBCS they had to study on regular basis and to put extra efforts to gain the required knowledge.

At start, we briefed students about the importance of using the proposed model for our course and how involving in classroom case studies along with role-based discussion can provide them a rich basis for developing their critical analysis, problem solving, and decision making skills. Before beginning, the students were guided for their roles and participation in the case studies so that they could harvest the maximum benefits from this exercise. Most importantly, the norm of the class was set to participation and collaboration, which included:

(a) preparation for the case;

(b) speaking about opinions, arguments, and analysis;

(c) listening others carefully for their arguments and giving feedback.

This encouraged every student to bring forth and test his thoughts and opinions, and the feedback they received either re-enforced their thoughts or modified them.

\section{B. Case Discussions}

In our methodology, we adopted discussion format as a design for case study. Our objective was to structure the discussion to develop the students' analytical skills and to ensure that their participation in the case is the maximum.

Initially, aiming at making a low pressure situation for the students and ignite their start-up with case studies, we discussed the cases given in the course reference book [13]. These cases are followed by several directed questions on the associated course topics as well as the associated situations. Through these small and easy cases, the students quickly got used to case studies. Later on, different large external cases on relatively complex topics in the course, pointed in the referenced book through their web links, were studied for more practice. However, while choosing cases, we took special care that each case should contain essential details of the circumstances at the time of real occurrence of the case and must not be so long that the students get bored in reading and making the tedious analysis. We particularly selected cases from last couple of years, which raised students' motivation and involvement in the case. In each large case study, the students were asked probing questions that focused their attention towards specific parts of the case. In the light of these questions and above guidelines, the students analyzed the problem depicted in the case to find answers of the questions. Further, through cross discussions, the students identified various issues and problems posed in the case, their possible solutions and consequences of these solutions.

In the beginning, students were given hints for preparing the cases and to go through typical phases of a case study through questions like:

- What is the situation presented in the case?

- Is any supplementary data provided with the case?

- Take notes as you go through the case;

- Find out the broad issues, problems and questions in the case;

- Make a list of the key problems in the case;

- Prioritize these problems according to their criticality;

- What are your recommended solutions for the problems?

- Support your opinions with empirical evidence and/or logical arguments;

- Evaluate and analyze your recommendations with alternatives;

- What are the consequences for your recommendations? Compare your recommendations with those of other students in the class;

- What actions should finally be taken?

- How can the outcomes of the case be generalized? etc.

In the second stage, students divided their responsibilities for searching the required information. Later, they demonstrated their findings and shared opinions about the unclear points. After mutual discussion, the students got cleared on some of the points and narrowed down their future search for new information. By the end of this stage, the students had 
obtained information they needed to understand the unclear points.

In the third and final stage, students were ready for discussion on the problems presented in the case. They shared their understanding, perspective, and data on the case. Usually students had different understandings (based on their background knowledge and searched data) and perspectives (based on the roles assigned to them), which resulted in different opinions on the presented problems, the relative importance of the problems and their solutions. This was the crux of the whole case study. They debated on several points, presented their arguments and tried to reach a consensus on the problems and their solutions. Although they could not find out the optimal/adopted solution to the problem, nevertheless, they came up with a set of proposed solutions to the case problems, and this served our purpose. The outcome of the case study is the understanding of several components including the case problems/opportunities, circumstances at the time of the case, different factors affecting the choice of the solution etc. Overall, this whole practice mimics the way we usually behave in our real-life. To ensure that the case studies got finished in the due class time, the students were assigned time slots to present their opinions. The discussion session were controlled by intimating them about the time left, 20 and 10 minutes before the ending time.

\section{Evaluation of the Proposed Model}

We evaluated the effectiveness of the proposed model in two ways: directly and indirectly. In direct evaluation, a survey comprising 16 questions was conducted at the end of each case. These questions targeted at the evaluation of cases, the exercise of case discussion, and learning of target skills. Our direct evaluation is in accordance with other similar studies like [11]. The questions were designed in a way so that their responses can be measured by Likert scale to facilitate comparison. We also adopted several survey questions from [11]. The survey questions along with their possible answers are listed in Table 1. In indirect evaluation, we compared students' grades of two sections taking the course. The result of our survey and comparison of students' grades are presented in next section.

\section{RESULTS AND ANALYSIS}

The proposed teaching model was applied on 28 undergraduate students taking the course TDSS at Department of Information Systems, Faculty of Computing and Information Technology, King Abdulaziz University, Jeddah, Saudi Arabia. The students' response to survey questions (as average of all the surveys) is illustrated in Fig. 1.

Through our survey, we found that students had spent a significant amount of time to answer and discuss review questions of the first case; however, they spend lesser time in the second one and so on. In general, they answered either in agreement (agree completely or to some extent) or "neutral" to most of the questions. Students' response to question\# 1 shows that $50 \%$ of the students did not agree that the cases were easy. However, we noticed that they were still able to solve the cases. This indicates that they made extra efforts to solve the cases. In response to question \# 2,71\% students were confident that they adopted the right way to prepare for the course. Whereas, $14 \%$ replied in agreement to some extent and $11 \%$ remained neutral. Responding to question\# 3,61\% of the students agreed to have enough time to search for the required resources to solve the case.

Replying to question\# 4, 75\% of students effectively located the required resources. From replies to questions 3 and 4 together, it is interesting to note that although $25 \%$ of students were in disagreement $(14.3 \%$ disagreed to some extent and $10.7 \%$ completely disagreed) to the time given to find the necessary resources, yet they were able to find them - no one disagreed to question \# 4. This indicates a psychological pressure of the case situation. From such occurrences, students learnt a very important lesson of being calm in decision making situations.

Table 1. Survey Questions and Answers.

\begin{tabular}{|c|c|c|}
\hline Ser. \# & Questions / Enquiries & Answers \\
\hline 1 & The case was easy to study. & \multirow{11}{*}{$\begin{array}{l}\text { Completely Agree / } \\
\text { Agree to some extent / } \\
\text { Neutral/ } \\
\text { Disagree to some extent / } \\
\text { Strongly Disagree }\end{array}$} \\
\hline 2 & My way of preparation for the case and associated discussion was effective. & \\
\hline 3 & $\begin{array}{l}\text { The time given to search for the necessary resources and to solve the case was } \\
\text { enough. }\end{array}$ & \\
\hline 4 & I was able to find necessary resources for case study. & \\
\hline 5 & I feel I understood the main problem and related issues in the case. & \\
\hline 6 & I was able to identify questions to be investigated further. & \\
\hline 7 & $\begin{array}{l}\text { I feel I have a better understanding of the process of decision making in real-life } \\
\text { after using this case. }\end{array}$ & \\
\hline 8 & My learning improved by working collaboratively on investigative cases. & \\
\hline 9 & I was able to provide well-supported conclusions/answers. & \\
\hline 10 & Most students were able to use convincing argumentation with their peers. & \\
\hline 11 & $\begin{array}{l}\text { My overall experience with case based learning is satisfactory so far and I would } \\
\text { like to use RBCS model again. }\end{array}$ & \\
\hline 12 & What did you like in learning using this case? & Open Answer \\
\hline 13 & What did you dislike in learning using this case? & Open Answer \\
\hline
\end{tabular}




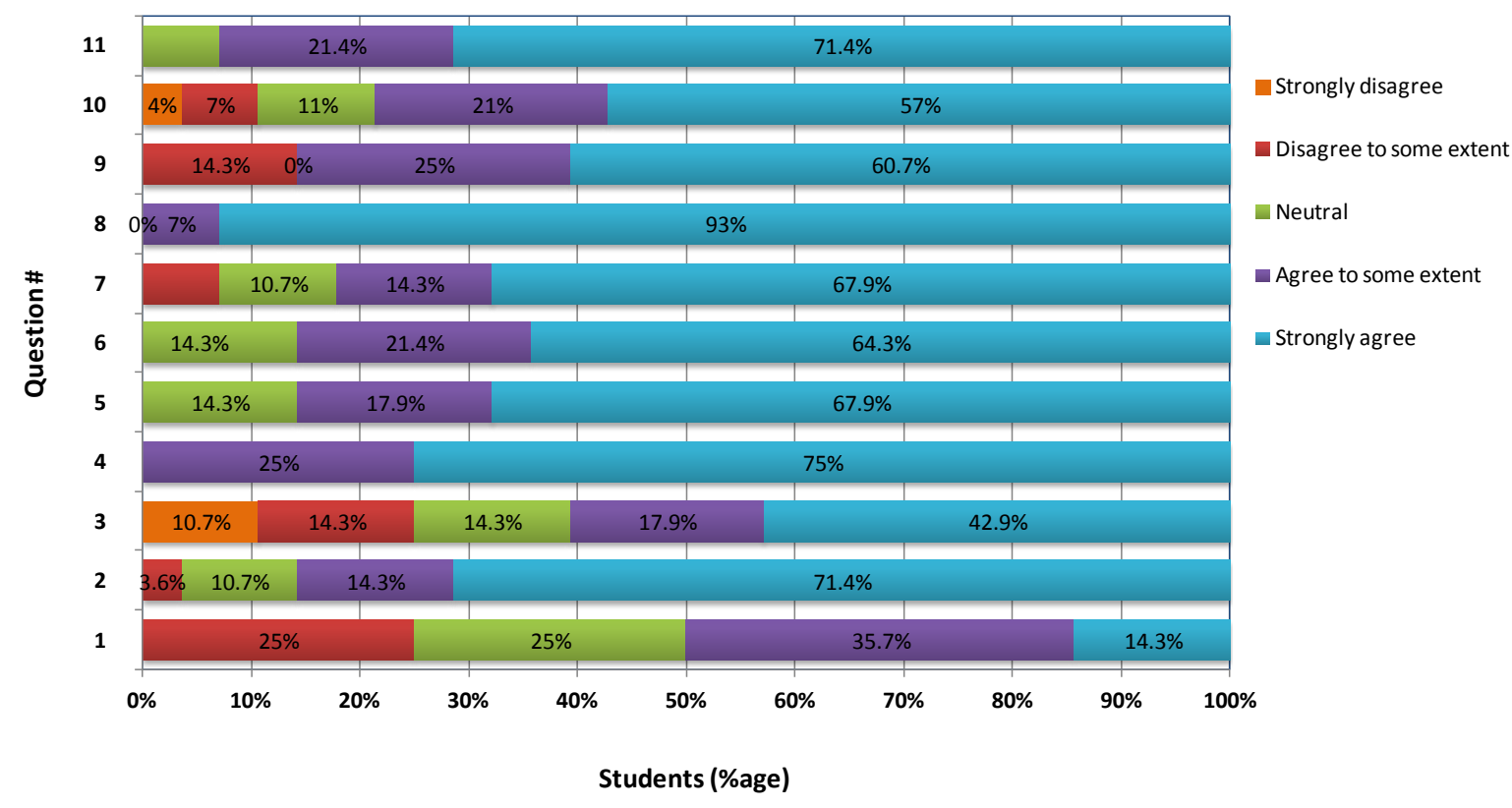

Fig. 1. Students' response to survey questions.

Responses to question\# 5 show that $85.8 \%$ $(67.9 \%+17.9 \%)$ of the students effectively understood the issues presented in the case and responses to question\# 6 show that they $(64.3 \%+12.4 \%)$ were also able to identify the main points for further investigation. In response to question\# 7,67.9\% of students felt that they had a better understanding of dynamics of decision making through case studies. In response to question\# $8,93 \%$ of students agreed that they benefited from collaborative case studies. Students' response to question\# 9 shows that $60.7 \%$ of the students were able to present well supported arguments/conclusions.

In response to our question\# 10 in the survey, we found that $43 \%(4 \%+7 \%+11 \%+21 \%)$ of the students were not completely convinced by the argumentation of their peers. Thus, they learnt that it is natural to have different opinions and it is very difficult to optimize all aspects. Overall, $92.8 \%$ of the students were satisfied from case based study (response to question\# 11).

Fig. 2 shows a comparison of students' marks in two different sections of our course TDSS, one of them was taught using the proposed RBCS model (in addition to class lectures), while the other was taught using lecturebased teaching model only. We noticed a clear improvement in students' performance in all the evaluations: quizzes, assignments, exams, project, and lab. On average, the proposed model raised students' marks by $13 \%$.

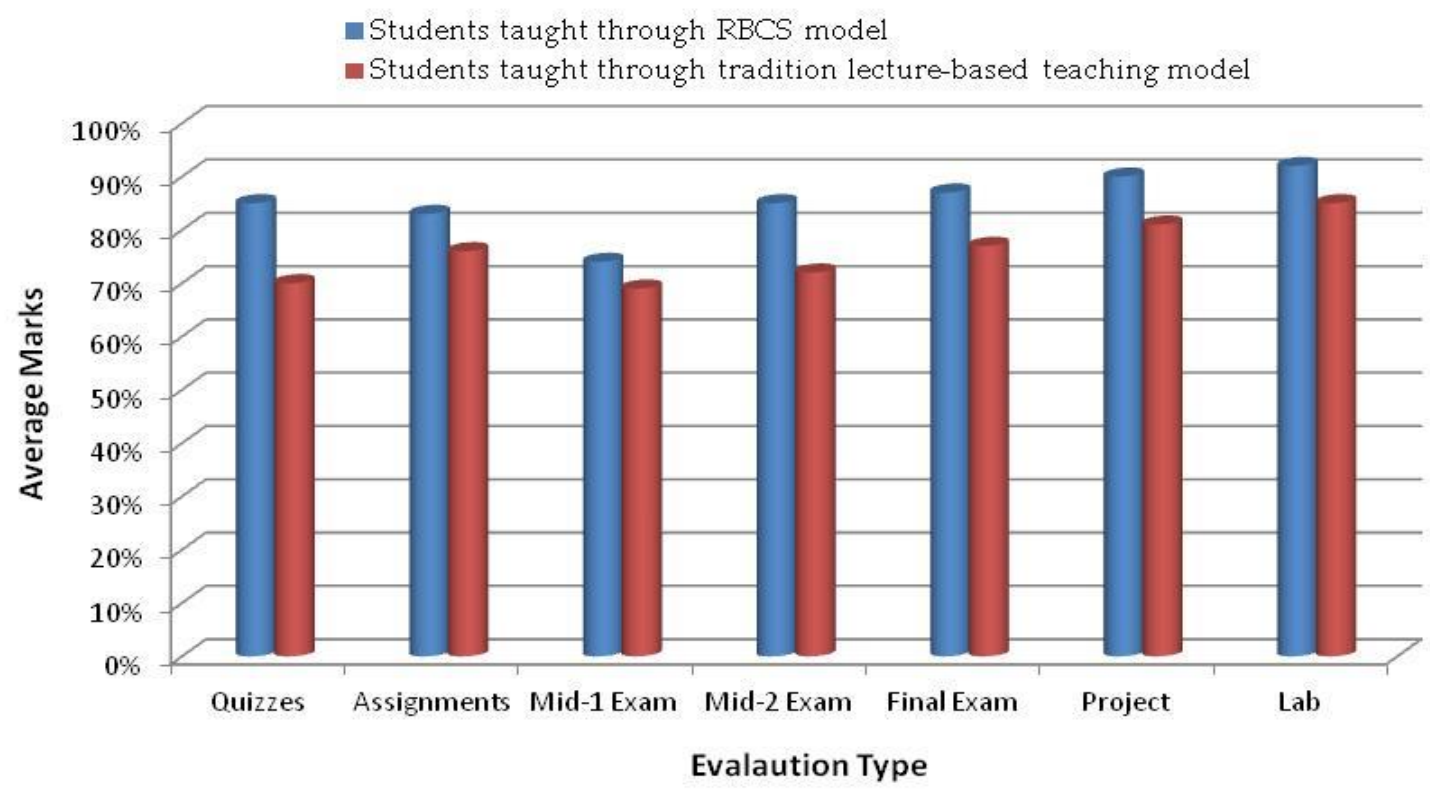

Fig. 2. Comparison of students' evaluations in two sections 


\section{CONCLUSION}

This paper shares our experience of using interactive case based learning as a new teaching model for the course TDSS. In contrast to traditional case studies, in RBCS students studied the cases by performing the roles of the stakeholders of the decision making situations. They actually tried to simulate the same decision making situation that was there at the time of actual case and thus had similar feelings as of the actual decision makers of the case. This exercise provides students a firsthand learning of how to optimize the situation for the best results where they might have to go through several trade-offs. The benefit of using the proposed learning model is fourfold: first, RBCS model teaches the key concepts and facts within the context of real-world examples. The real context of the problem (as described in the case) provides a concrete framework of the problem and therefore, is more motivational to the students. Second, through cases, complex concepts in the decision support process can be more easily understood. Third, RBCS reduces the possibility of "inert" knowledge. Last but not the least, exploring story like, real-life cases, increases collaborative learning among students, which provides context and necessary resources to discuss and debate issues and can guide students to reach a conclusion. We found students more satisfied and having higher grades after adopting the proposed model in our course.

\section{REFERENCES}

[1] Barnes, M. 2013. Role Reversal: Achieving Uncommonly Excellent Results in the Student-centered Classroom, ASCD, ISBN: 9781416615064.

[2] Froyd, J. and Simpson, N. 2008. Student-centered learning addressing faculty questions about student centered learning. http://ccliconference.org/files/2010/03/Froyd_Stu CenteredLearning.pdf

[3] Pashler H., Bain, P. M., Bottge, B. A., Graesser, A., Koedinger, K., McDaniel, M., Metcalfe, J. 2007. Organizing Instruction and Study to Improve Student Learning. http://ies.ed.gov/ncee/wwc/pdf/practice_guides/ 20072004.pdf

[4] Speaking of Teaching, Stanford university newsletter on teaching. Winter 1994, vol. 5, no. 2. http://www.stanford. edu/dept/CTL/cgi-bin/docs/newsletter/case_studies.pdf.

[5] Pashler, H., Bain, P. M., Bottge, B. A., Graesser, A., Koedinger, K., McDaniel, M., \& Metcalfe, J. (2007). Organizing Instruction and Study to Improve Student Learning. IES Practice Guide. NCER 2007-2004. National Center for Education Research.

[6] University of Michigan: Center for research on learning and teaching, Teaching Strategies: Case-based Teaching and Problem-based Learning, http://www.crlt.umich.edu/ tstrategies/tscbt.php.

[7] Marzano, R. J., Norford, J. S., Paynter, D. E., Pickering, D. J., \& Gaddy, B. B. A Handbook for Classroom Instruction That Works: Research-Based Strategies for Increasing Student Achievement. 2001. USA: McREL.

[8] Jarz, E. M., Kainz, G. A., \& Walpoth, G. (1997). Multimedia-based case studies in education: Design, development, and evaluation of multimedia-based case studies. Journal of Educational Multimedia and Hypermedia, 6 (1), 23-46.

[9] John F., The Case Method and the Interactive Classroom in Thought and Action, vol. 17, no. 1 pp. 41-51, 2001.

[10] Merseth, K. (1991). The early history of case-based instruction: Insights for teacher education today. Journal of Teacher Education, 42 (4), 243-249.

[11] Emmanuel N., Eric L., Avi O. and David W., Case Studies for Environmental and Water Resources Systems Analysis Education, World Environmental and Water Resource Congress 2006, Chapter 82, pages 1-6, http://ascelibrary. org/doi/abs/10.1061/40856\%28200\%2983.

[12] Golich VL. Mark B., Patrice Franko, Steve Lemy, The $\mathrm{ABCs}$ of case teaching. International Studies Perspectives. 2000; 1:11-29.

[13] Decision Support and Business Intelligence Systems (8th Edition) Prentice-Hall, Inc. Upper Saddle River, NJ, USA 2006, ISBN: 0131986600.

[14] Likert, R.A., 1932. Technique for the measurement of attitudes. Archives of Psychology, 140: 1- 55.

[15] Donaldson Joe F. (2009). "Fostering Transformative Learning in Leadership Development.” In Mezirow, J., Taylor, E., \& Associates (Eds.), Transformative Learning in Practice: Insights from Community, Workplace, and Higher Education, 57-66. San Francisco: Jossey-Bass.

[16] Mezirow, J., 1996, Contemporary paradigms of learning. Adult Education Quarterly, 46(3), 158-173.

[17] Gilbert B., Pierre-Majorique L., Jacques R., and Simon Bourdeau, ERPsim BI: a Problem-based Learning approach in Teaching Business Analytics, In Proceedings of DYNAA 2011, vol.2, no. 1 .

[18] Dochy, F., Segers, M., Van Den Bossche, P., \& Gijbels, D (2003). Effects of problem-based learning: A metaanalysis. Learning and instruction, 13(5), 533-568.

[19] Brush, T., \& Saye, J. (2000). Implementation and evaluation of a student-centered learning unit: A case study. Educational technology research and development, 48(3), 79-100.

[20] Dochy, F., Segers, M., Van Den Bossche, P., \& Gijbels, D. 2003. Effects of problem-based learning: A meta-analysis. Learning and instruction, 13(5), 533-568.

[21] Nair, S. P., Shah, T., Seth, S., Pandit, N., \& Shah, G. V. 2013. Case Based Learning: A Method for Better Understanding of Biochemistry in Medical Students. Journal of clinical and diagnostic research: JCDR, 7(8), 1576.

[22] Yu, B., Chan, P., Chan, S. F., \& Chang, J. 2014. Exploring the preference in learning approach among the Hong Kong university students: case study, problembased or traditional textbook question. Developments in Business Simulation and Experiential Learning, 32.

\section{Authors' Profiles}

Farrukh Nadeem received his Ph.D. in 2009 from the University of Innsbruck, Austria. Since July 2009, he has been working as an Assistant Professor. His main research interests include performance modeling and prediction, and scheduling scientific workflows in distributed systems, particularly the Grid and the Cloud. He has been involved in a several Austrian and Saudi research and development projects. Farrukh is an author of more than 22 papers, including four book chapters. He is holder of several distinctions and awards during his educational 
career.

Salma Mahgoub received her M.Sc. degree in Computer Science from University of Khartoum in 2006. She is a lecturer at Department of Information Systems, King Abdulaziz University. She has been teaching different courses to undergraduate students in different fields like computer and information security, decision support systems, principles of information systems and data mining. Her research interests include information security, data mining, genetic fuzzy systems and expert systems.

How to cite this paper: Farrukh Nadeem, Salma Mahgoub,"Student-centered Role-based Case Study Model to Improve Learning in Decision Support Systems", IJMECS, vol.6, no.10, pp.16-22, 2014.DOI: $10.5815 /$ ijmecs.2014.10.03 